\title{
Editorial
}

\section{Nuevo organigrama directivo de Actas Urológicas Españolas}

\author{
José L. Ruiz Cerdá \\ Servicio de Urología. Hospital Universitario La Fe de Valencia, España
}

$\mathrm{R}^{\mathrm{c}}$ cientemente, ACTAS ha sido incluida en Science Citation Index Expanded (SCI-E), indice de citas del Institute for Scientific Information. Lo cual significa entrar a formar parte de la selectiva base de datos de revistas científicas a partir de la cual se elabora el Journal Citation Report. El primer factor de impacto de la historia de ACTAS verá la luz a mediados del 2010 y reflejará el producto de las citaciones que la revista reciba de los trabajos publicados durante 2008 y 2009.

Por otra parte, durante el último congreso nacional, la Confederación Americana de Urología (CAU) decidió que ACTAS pasaba a ser su revista oficial. De esta forma, se convierte en una revista urológica de ámbito internacional con una posición estratégica privilegiada por su gran potencial divulgativo. Ya que, es la única en lengua española incluida en el SCI-E y, a su vez, está abierta a los lectores anglosajones por estar traducida al inglés.

Estos dos hechos decisivos en la historia de nuestra revista hacen que concluya una etapa y comience otra con objetivos diferentes. Por un lado, es necesario conseguir el mayor número de citas en revistas de impacto. Por otra, se deben llevar a cabo acciones para conseguir que la revista sea el referente de la comunidad urológica hispanohablante. Para alcanzar estos objetivos se ha diseñado un plan estratégico. Dicho plan fue presentado en la última reunión plenaria de la Junta Directiva de la Asociación Española de Urología (AEU) celebrada el 21 de Noviembre de 2008. Dentro de las herramientas organizativas y funcionales del plan estratégico, se encuentra la creación de un nuevo organigrama directivo adaptado a las necesidades actuales.

El nuevo organigrama consta de un director que se encargará de dirigir la revista y de elaborar el plan estratégico. En representación de la AEU y de la CAU, se han establecido dos co-directores. Su función esencial será la de facilitar las relaciones con las asociaciones respectivas y con otras asociaciones internacionales. Además, ayudaran a la difusión de la revista en los congresos. El co-director de la AEU es el doctor Carlos Llorente, actual vocal de actividades científicas. El de la CAU es el doctor Rodríguez Netto. El peso de la gestión editorial recaerá en cuatro directores asociados con funciones muy específicas. El doctor Alberto Budía se encargará de la calidad formal de la revista y del programa de control de autocitación. El doctor Francisco Sánchez será encargado de la visibilidad y accesibilidad de la revista. El doctor Federico Rodríguez-
Rubio se encargará de la obtención de artículos que sean potencialmente citables o que diferencie a la revista de la oferta de otras. El doctor Octavio Castillo será el editor asociado para los temas específicos de Sudamérica. Por último, en el nuevo organigrama, se ha procedido a la unificación de los Comités de Redacción y Consejo Científico en un único Comité de Redacción. Los miembros de este nuevo comité tendrán un papel decisivo y se encargarán, además del proceso de revisión, de realizar pequeños comentarios editoriales sobre trabajos publicados en la revista o sobre temas de interés que favorezcan la citación. $\mathrm{El}$ criterio por el que se han elegido a los miembros de este comité ha sido variado. Urólogos jóvenes emergentes, urólogos significados por su compromiso con ACTAS, urólogos caracterizados por su trayectoria científica y urólogos procedentes de Sudamérica recomendados por la CAU. Si no existe más participación sudamericana no es por falta de voluntad. Se ha intentado incorporar al comité urólogos de todos los países, pero la respuesta ha sido muy variada y poco uniforme. De todas formas, el comité no está cerrado y es nuestra intención que exista un recambio constante que lo dinamice y actualice.

Para poder llevar a cabo el proceso editorial vamos a contar con la ayuda de todo el personal de la Editorial ENE. En especial, del trabajo esencial y apasionado de Rosaura y de la inestimable ayuda de María Jesús.

Desde aquí, me gustaría agradecer de antemano a todas las personas que se han incorporado con ilusión y están dispuestas a trabajar para nuestra revista. La recompensa por su labor no va ser de tipo material. Son conscientes de que su contribución forma parte de un nuevo proyecto común por el que merece la pena apostar llamado ACTAS. También, quisiera expresar mi agradecimiento a todas aquellas que con su esfuerzo y dedicación nos han conducido hasta aquí. A los miembros del comité científico porque son personalidades esenciales de la historia más actual en la urología española. A los miembros del antiguo comité de redacción por su esfuerzo callado y totalmente desinteresado en la revisión de artículos. A los vocales de actividades científicas y a los directores anteriores porque, cada uno en su etapa, innovaron, avanzaron y acertaron eligiendo la dirección correcta para la revista. A todos los autores que han contribuido con sus trabajos y, por supuesto, a todos los lectores que nos siguen.

José Luis Ruiz Cerdá Director de Actas Urológicas Españolas 